\title{
Skin Cancer and Dermoscopy Training for Primary Care Physicians: A Pilot Study
}

\author{
Valeria De Bedout ${ }^{1}$, Natalie M. Williams ${ }^{1}$, Ana M. Muñoz ${ }^{2}$, Ana M. Londoño ${ }^{2}$, \\ Manuela Munera², Natalí Naranjo², Lina M. Rodriguez², Alejandra M. Toro², \\ Feng Miao $^{3}$, Tulay Koru-Sengul ${ }^{3,4}$, Natalia Jaimes ${ }^{1,4}$
}

1 Dr. Phillip Frost Department of Dermatology and Cutaneous Surgery, University of Miami Miller School of Medicine, Miami, Florida, USA 2 Department of Dermatology, Universidad Pontificia Bolivariana, Medellin, Colombia

3 Department of Public Health Sciences, University of Miami Miller School of Medicine, Miami, Florida, USA

4 Sylvester Comprehensive Cancer Center, Miami, Florida, USA

Key words: skin cancer, dermoscopy, dermoscopy training, diagnostic accuracy

Citation: De Bedout V, Williams NM, Muñoz AM, Londoño AM, Munera M, Naranjo N, Rodriguez LM, Toro AM, Miao F, KoruSengul T, Jaimes N. Skin cancer and dermoscopy training for primary care physicians: a pilot study. Dermatol Pract Concept. 2021;11(1):e2021145. DOI: https://doi.org/10.5826/dpc.1101a145

Accepted: September 22, 2020; Published: January 29, 2021

Copyright: $@ 2021$ De Bedout et al. This is an open-access article distributed under the terms of the Creative Commons Attribution License BY-NC-4.0, which permits unrestricted noncommercial use, distribution, and reproduction in any medium, provided the original author and source are credited.

Funding: This study was funded by the Sylvester Comprehensive Cancer Center Global Oncology Innovation Grant. Research reported in this publication was supported by the National Cancer Institute of the National Institutes of Health under Award Number P30CA240139. The content is solely the responsibility of the authors and does not necessarily represent the official views of the National Institutes of Health..

Competing interests: The authors have no conflicts of interest to disclose.

Authorship: All authors have contributed significantly to this publication.

Corresponding author: Natalia Jaimes, MD, Dr. Phillip Frost Department of Dermatology and Cutaneous Surgery, University of Miami Miller School of Medicine, Dermatology Research Clinic, 1600 NW $10^{\text {th }}$ Ave, RSMB 2023A. Miami, Florida, 33136, USA. Email: njaimes@med.miami.edu

ABSTRACT Introduction: The primary objective of this study was to determine the diagnostic accuracy and effect of an educational training on skin cancer course and dermoscopy use among primary care physicians in rural areas of Colombia. The secondary objective was to assess the diagnostic accuracy of skin cancer diagnosis and detection rate after 3 months of the initial training.

Methods: Twenty-one primary care physicians from 6 rural areas of Colombia participated in a 2-day skin cancer and dermoscopy training, followed by a day-long hands-on session on dermoscopy at a free skin cancer screening event. Pre- and post-tests were performed using clinical and dermoscopic images to evaluate the user's ability to diagnose and differentiate benign and malignant neoplasms. In addition, participants' levels of confidence were assessed.

Results: After the training, the sensitivity and specificity of characterizing skin lesions as benign or malignant or providing a specific diagnosis (ie, angioma, seborrheic keratosis, basal cell carcinoma, etc.) increased by $23.6 \%(62.9 \%$ to $86.5 \% ; \mathrm{P}<0.0001)$ and $21 \%(54.7 \%$ to $75.7 \%$; $\mathrm{P}<0.0017)$, respectively. In addition, levels of confidence when diagnosing skin lesions changed from extremely low or low, to high or extremely high by $20.7 \%$ (38.3\% to $59 \%$ ) using dermoscopic images (odds 
ratio (OR) 3.22; $95 \%$ confidence interval $(\mathrm{CI}): 2.67-3.86 ; \mathrm{P}<0.0001)$. The secondary objective was not achieved due to loss of follow-up of the majority of participants.

Conclusion: Providers serving populations with limited healthcare access may benefit from education in diagnosing and differentiating skin cancer with the use of dermoscopy, which may ultimately improve patient care and reduce healthcare costs.

\section{Introduction}

Primary care physicians (PCPs) play a critical role in the health system of many Latin American countries. PCPs are usually the first physicians to encounter the patient and are responsible for the decision-making as to whether or not a patient needs further evaluation. Among dermatologic conditions, skin cancer continues to be a public health burden worldwide and most cases can be cured if detected early. Thus, early detection is paramount in improving patient prognosis and quality of life, while reducing healthcare costs. Various strategies, both in primary and secondary prevention, have been suggested and implemented including education for medical and non-medical communities. In fact, different educational interventions for PCPs have been developed within the field of skin cancer, but few have been carried out in Latin America [1] .

Dermoscopy is a noninvasive, in-vivo imaging technique that allows the visualization of subsurface structures of the skin that are otherwise not visible to the naked eye [2,3]. Traditionally, dermoscopy has been used by, and taught to, dermatologists. However, during the last decade its use has been explored and extended to PCPs [4-6]. Although dermoscopy increases the diagnostic accuracy of skin cancer diagnosis, this improvement is contingent on acquiring dermoscopy training. Without training, the use of dermoscopy may result in poorer performance compared to clinical examination [7-9]. It has been shown that PCPs who are trained in dermoscopy not only improve their sensitivity for the diagnosis of skin cancer, but also reduce the number of unnecessary biopsies and referrals [4-6]. Oftentimes, there is a lack of specialized medicine (eg, dermatology) in underserved populations including rural areas of countries such as Colombia. In these populations the PCP may represent the first, and sometimes the only, healthcare provider. Thus, having PCPs trained in diagnosing and differentiating skin cancer using dermoscopy would be an efficient strategy to improve the early detection of skin cancer and consequently reduce morbidity and associated healthcare costs.

The present pilot study developed a skin cancer and dermoscopy training intervention for PCPs in the Eastern rural region of the Department of Antioquia in the country of
Colombia. The Department of Antioquia is the second most populated Department of Colombia among its 32 departments, with an estimated population of 6.4 million. Antioquia is located in the central northwestern part of Colombia with most of its territory being part of the Andes mountain range. The racial background of this region is largely mestizo and white. These individuals are more prone to developing skin cancer because of their skin phenotype, increased ultraviolet radiation (UVR) exposure due to their frequent outdoor activities (eg, agriculture), and the geographic location of their municipalities at high altitudes with high UVR indexes yearround [10]. The primary objective of this study was to determine the diagnostic accuracy and effect of an educational training on skin cancer and dermoscopy use among PCPs in this rural region of Colombia. The secondary objective was to assess the diagnostic accuracy of skin cancer diagnosis and detection rate after 3 months of the initial training.

\section{Methods}

\section{Study design and population}

PCPs from hospitals of 6 municipalities in the rural area of the Eastern Region of Antioquia, Colombia (ie, Alejandría, El Peñol, Guatapé, Marinilla, San Carlos, and San Rafael) were invited to participate in the study in November of 2018. This area was selected given its geographic location combined with its low healthcare access, offering level 1 or 2 medical services without specialized medicine. The total population for these 6 municipalities is 111,175 . The study was IRB-approved at the Universidad Pontificia Bolivariana in Medellín, Colombia.

\section{Intervention: Training in Skin Cancer and Dermoscopy}

Inclusion criteria consisted of healthcare professionals working in primary care settings who were willing to voluntarily participate in the study. Individuals who did not complete both pre- and post-tests or did not attend at least $50 \%$ of the course were excluded. PCPs participating in the study received a 2 -day course on the theoretical and practical aspects of diagnosing and differentiating skin cancer clinically and with dermoscopy. Training was provided by 
5 dermatology residents and 2 dermatologists with expertise in dermoscopy. A quasi-experimental study with a pre-test/ post-test design was performed. A total of 50 cases were presented on a large screen using PowerPoint before and after training. First, the clinical images of all 50 cases ( 24 benign, 26 malignant) were presented. For each case, 3 questions were asked: 1) Is the lesion benign or malignant? 2) What is the possible diagnosis (seborrheic keratosis [SK], nevus, squamous cell carcinoma [SCC], melanoma, or other)? and 3) What is the level of confidence (on a scale from 1 to 5 , with 1 being not confident and 5 being extremely confident)? Examiners recorded their responses by writing their answer choice on a paper-based test. After completion of the presentation of clinical images, the cases were presented again with the addition of a dermoscopic image as demonstrated in Figure 1, and the same 3 questions were answered. After the 2-day course, the same 50 cases were presented using the same format and questions (post-test). Each trainee was given 1 minute to respond to each case in both the pre- and post-examinations. Additionally, participants were instructed not to discuss the cases after the pre-test. A few of the test images were included by way of illustration or discussion in the teaching activities. Subsequently, participants joined a 1-day hands-on session with one-on-one training during a free skin cancer screening event offered to local communities. Each participating institution was provided with a dermoscope to use after training.

\section{Statistical Analysis}

Descriptive statistics were used to describe the demographic information and other characteristics of the study participants including gender, type of practice (private vs public), years of practice, average of cases of dermatologic conditions seen per months, and knowledge about dermoscopy, self-skin examination, and full body skin examination. To evaluate the training intervention, pre-test and post-test results were measured. Measures of validity included the sensitivity and specificity of diagnostic accuracy, and Kappa statistics for agreement and overall percent agreement. Dichotomous outcome measurements were created using the data provided by the participants. Variables included: 1) benign vs malignant and 2) possible diagnosis. The values of these variables were used to create cross-classifications of benign and malignant lesions and to calculate overall sensitivity, specificity, overall agreement and Kappa statistics with 95\% confidence intervals (CI) for both pre-test and post-test. To evaluate the improvement after the 2-day course, we used McNemar's test to compare sensitivities, specificities, and overall agreement between pre-test and post-test. The association between diagnosis confidence and training were estimated by odds ratio (OR) with corresponding $95 \% \mathrm{CI}$ and $\mathrm{P}$ value. Data
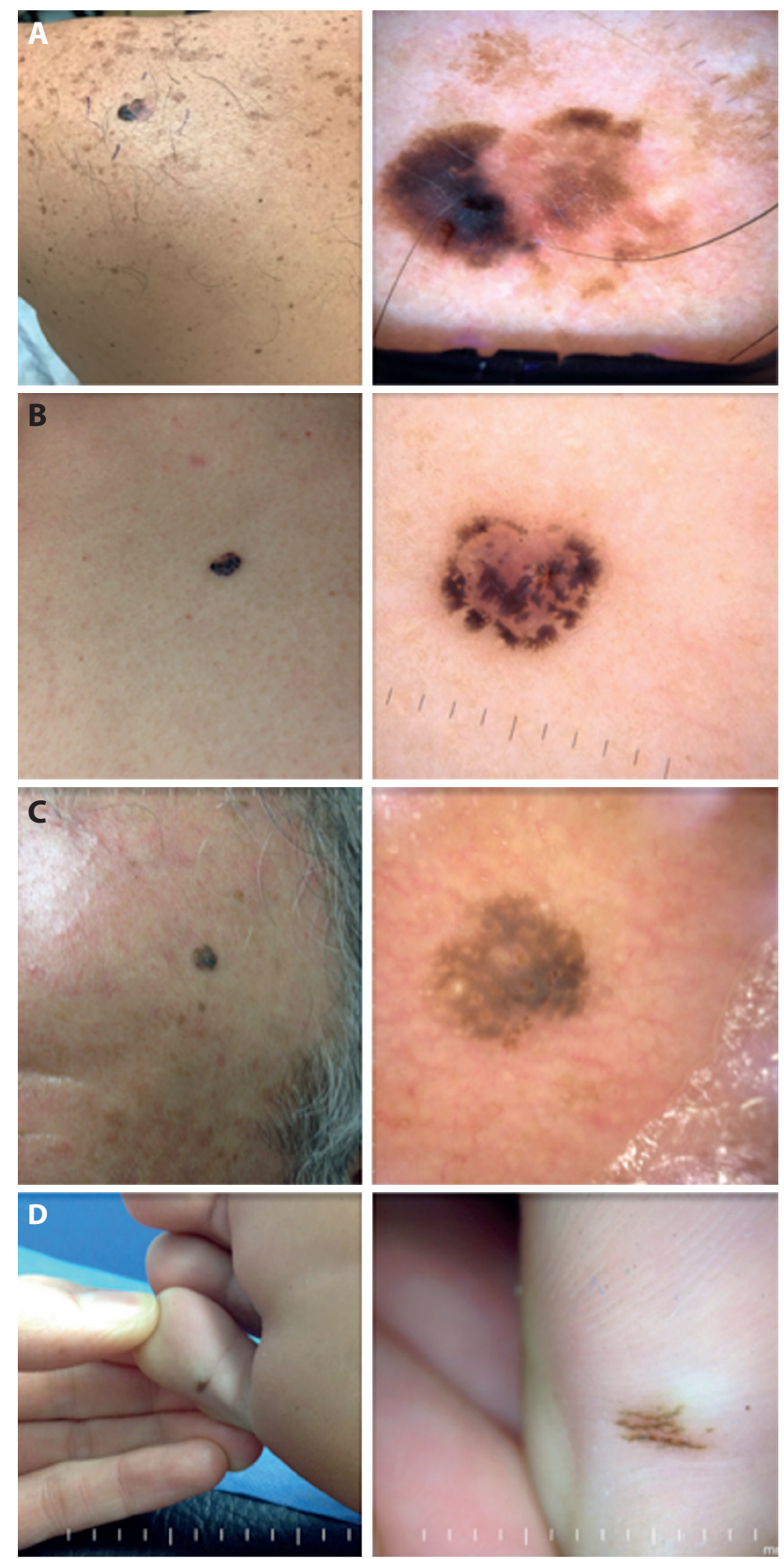

Figure 1. Test images. Clinical and dermoscopic images of various skin lesions were presented separately during the pre-test and posttest. For each case, a clinical image (left) was presented followed by the clinical and dermoscopy (right) image: (A) melanoma, (B) basal cell carcinoma (C) seborrheic keratosis, and (D) acral nevus.

management all of the statistical analyses were carried out using SAS v9.4 (SAS Institute Inc., Cary, NC, USA).

\section{Three-Month Follow-up}

To evaluate the longer-term effects of the intervention, a 3-month follow-up of the PCPs was planned to learn whether the training was serving the target population. For this phase of the study, an online rehearsal course in dermoscopy was offered to the participating PCPs. In addition, PCPs and hospitals were asked to provide a de-identified list of patients with skin cancer diagnoses that were seen by the participating 
PCPs 3 months prior to and 3 months after the training course. For this list, the International Statistical Classification of Diseases and Related Health Problems $10^{\text {th }}$ Revision codes (ICD-10) were used.

\section{Results}

A total of 21 PCPs from 6 hospitals of 6 municipalities participated in the course. Two physicians were present for less than half of the course; therefore, 19 PCPs were included in the final analysis. Demographics of the PCPs are listed in Table 1, and information on their current understanding and clinical practice with respect to skin cancer is listed in Table 2.

\section{Two-Day Skin Cancer and Dermoscopy Training}

1. Benign vs Malignant

The PCPs ability to differentiate malignant lesions (ie, melanoma, BCC, and SCC) from benign lesions (ie, nevus, dermatofibroma, angioma, and SK) was tested and analyzed using pre- and post-test evaluations. Of the test cases, $48 \%$ of lesions were benign. Pre- and post-test results are demonstrated in Table 3. The sensitivity for skin cancer diagnosis using clinical images alone was $57.8 \%$, improving to $71.8 \%$ $(\mathrm{P}<0.0001)$ using clinical images alone, and $83.9 \%(\mathrm{P}<$ 0.0001 ) using clinical and dermoscopy images. The specificity also increased from $58.5 \%$ to $66.1 \%$ (clinical images alone, $\mathrm{P}=0.0107$ ) and $78 \%$ (clinical and dermoscopy images,

Table 1. Characteristics of the Healthcare Professionals in the Study

\begin{tabular}{|l|r|r|}
\hline \multicolumn{1}{|c|}{ Participant Characteristics } & $\mathbf{n}$ & $\%$ \\
\hline All & 21 & 100.0 \\
\hline Gender & 11 & 52.4 \\
\hline Female & 10 & 47.6 \\
\hline Male & & \\
\hline Job type of the healthcare professional & 18 & 85.7 \\
\hline MD & 1 & 4.8 \\
\hline Nurse & 2 & 9.5 \\
\hline Other & \multicolumn{2}{|l|}{} \\
\hline Where do you work? & 3 & 14.3 \\
\hline Unanswered & 11 & 52.4 \\
\hline Community hospital & 1 & 4.8 \\
\hline Private hospital & 6 & 28.6 \\
\hline Private practice & 2 & 9.5 \\
\hline Years of practice & 15 & 71.4 \\
\hline Unanswered & 4 & 19.0 \\
\hline$<5$ & \multicolumn{2}{|r|}{} \\
\hline >5 & \multicolumn{2}{|l}{} \\
\hline
\end{tabular}

Table 2. Skin Cancer Knowledge and Practices of Healthcare Professionals in the Study

\begin{tabular}{|l|c|c|}
\hline $\begin{array}{c}\text { Participant Skin Cancer Knowledge } \\
\text { and Practices }\end{array}$ & n & $\%$ \\
\hline All & 21 & 100.0 \\
\hline
\end{tabular}

Number of dermatology conditions seen per week

\begin{tabular}{|l|r|r|}
\hline Unanswered & 9 & 42.9 \\
\hline 1 & 3 & 14.3 \\
\hline 2 & 2 & 9.5 \\
\hline 3 & 2 & 9.5 \\
\hline 4 & 1 & 4.8 \\
\hline 5 & 3 & 14.3 \\
\hline 20 & 1 & 4.8 \\
\hline
\end{tabular}

Number of dermatology conditions seen per month

\begin{tabular}{|l|r|r|}
\hline Unanswered & 11 & 52.4 \\
\hline 1 & 1 & 4.8 \\
\hline 2 & 1 & 4.8 \\
\hline 3 & 2 & 9.5 \\
\hline 5 & 2 & 9.5 \\
\hline 6 & 1 & 4.8 \\
\hline 10 & 1 & 4.8 \\
\hline 20 & 2 & 9.5 \\
\hline Cases of skin cancer seen per month & \multicolumn{2}{|r|}{} \\
\hline Unanswered & 7 & 33.3 \\
\hline 0 & 5 & 23.8 \\
\hline 1 & 5 & 23.8 \\
\hline 2 & 3 & 14.3 \\
\hline 3 & 1 & 4.8 \\
\hline
\end{tabular}

Do you know what a dermatoscope is?

\begin{tabular}{|l|r|r|}
\hline No & 0 & 0.0 \\
\hline Yes & 21 & 100.0 \\
\hline Have you used a dermatoscope? & & \\
\hline No & 14 & 66.7 \\
\hline Yes & 7 & 33.3 \\
\hline \multicolumn{3}{|l}{} \\
\hline Have you heard of self-skin exams? & 8 & 38.1 \\
\hline No & 13 & 61.9 \\
\hline
\end{tabular}

Do you discuss self-skin examinations with patients?

\begin{tabular}{|l|l|l|}
\hline Unanswered & 9 & 42.9 \\
\hline No & 6 & 28.6 \\
\hline Yes & 6 & 28.6 \\
\hline
\end{tabular}

How often should self-exams be performed?

\begin{tabular}{|l|r|r|}
\hline Unanswered & 15 & 71.4 \\
\hline Monthly & 2 & 9.5 \\
\hline Once a year & 2 & 9.5 \\
\hline Other & 1 & 4.8 \\
\hline Weekly & 1 & 4.8 \\
\hline
\end{tabular}

(Table 2 continues) 
Table 2. Skin Cancer Knowledge and Practices of Healthcare Professionals in the Study (continued)

\begin{tabular}{|c|c|c|}
\hline $\begin{array}{c}\text { Participant Skin Cancer Knowledge } \\
\text { and Practices }\end{array}$ & $\mathbf{n}$ & $\%$ \\
\hline \multicolumn{3}{|l|}{ Do you know the ABCDs of melanoma? } \\
\hline No & 4 & 19.0 \\
\hline Yes & 17 & 81.0 \\
\hline \multicolumn{3}{|c|}{ Do you discuss sun protection measures with patients? } \\
\hline Unanswered & 2 & 9.5 \\
\hline Yes & 19 & 90.5 \\
\hline \multicolumn{3}{|c|}{$\begin{array}{l}\text { How often do you perform full body skin exam on your } \\
\text { patients? }\end{array}$} \\
\hline Unanswered & 6 & 28.6 \\
\hline Never & 3 & 14.3 \\
\hline Every visit & 2 & 9.5 \\
\hline Once a year & 2 & 9.5 \\
\hline Twice a year & 1 & 4.8 \\
\hline Other & 7 & 33.3 \\
\hline
\end{tabular}

$\mathrm{P}<0.0001$ ) (Figure 2). Overall, after the educational intervention, the PCPs' ability to accurately identify lesions as benign or malignant significantly improved.

\section{Specific Diagnosis}

The PCPs ability to specifically diagnose benign (ie, angioma, nevus, dermatofibroma, SK) or malignant lesions (ie, BCC, SCC, melanoma) was tested and analyzed using pre- and post-test evaluations. Of the test cases, $22 \%$ were melanoma, $20 \%$ BCC, $10 \%$ SCC, $18 \%$ nevi, 10\% SK, $8 \%$ solar lentigo, $4 \%$ dermatofibroma and hematoma, and $2 \%$ angioma and angiokeratoma. The sensitivity for any skin cancer using clinical images alone was $60.1 \%$, improving to $72.4 \%$ (clinical images alone, $\mathrm{P}<0.0001$ ) and $85.4 \%$ (clinical and dermoscopy images, $\mathrm{P}<0.0001)$. The specificity increased from $59.4 \%$ to $66.8 \%$ (clinical images alone, $\mathrm{P}=0.012$ ) and $77.3 \%$ (clinical and dermoscopy images, $\mathrm{P}<0.0001$ ) (Figure 3).

\section{Confidence}

After the educational intervention, the number of participants who labeled their level of confidence when diagnosing skin

Table 3. Participant Responses on Pre- and Post-Tests

\begin{tabular}{|c|c|c|c|c|c|c|c|c|}
\hline & \multicolumn{2}{|c|}{ Pre-Test Clinical } & \multicolumn{2}{|c|}{ Pre-Test Dermoscopic } & \multicolumn{2}{|c|}{ Post-Test Clinical } & \multicolumn{2}{|c|}{ Post-Test Dermoscopic } \\
\hline & $\mathbf{n}$ & $\%$ & $n$ & $\%$ & $n$ & $\%$ & $n$ & $\%$ \\
\hline All images & 1,000 & 100.0 & 1,050 & 100.0 & 952 & 100.0 & 952 & 100.0 \\
\hline \multicolumn{9}{|c|}{ Accuracy (benign vs malignant) } \\
\hline Correct & 282 & 28.2 & 305 & 29.0 & 324 & 34.0 & 429 & 45.1 \\
\hline Incorrect & 702 & 70.2 & 743 & 70.8 & 561 & 58.9 & 462 & 48.5 \\
\hline Unanswered & 16 & 1.6 & 2 & 0.2 & 67 & 7.0 & 61 & 6.4 \\
\hline \multicolumn{9}{|l|}{ Nature of lesion } \\
\hline Benign & 487 & 48.7 & 519 & 49.4 & 409 & 43.0 & 409 & 43.0 \\
\hline Malignant & 502 & 50.2 & 528 & 50.3 & 478 & 50.2 & 482 & 50.6 \\
\hline Unanswered & 11 & 1.1 & 3 & 0.3 & 65 & 6.8 & 61 & 6.4 \\
\hline \multicolumn{9}{|l|}{ Diagnosis } \\
\hline Melanoma & 282 & 28.2 & 285 & 27.1 & 288 & 30.3 & 241 & 25.3 \\
\hline BCC & 115 & 11.5 & 137 & 13.0 & 107 & 11.2 & 137 & 14.4 \\
\hline SCC & 98 & 9.8 & 106 & 10.1 & 81 & 8.5 & 111 & 11.7 \\
\hline Nevus & 207 & 20.7 & 228 & 21.7 & 174 & 18.3 & 184 & 19.3 \\
\hline SK & 79 & 7.9 & 65 & 6.2 & 71 & 7.5 & 69 & 7.2 \\
\hline Dermatofibroma & 35 & 3.5 & 60 & 5.7 & 39 & 4.1 & 52 & 5.5 \\
\hline Angioma & 95 & 9.5 & 98 & 9.3 & 65 & 6.8 & 41 & 4.3 \\
\hline Other benign & 73 & 7.3 & 69 & 6.6 & 60 & 6.3 & 56 & 5.9 \\
\hline Unanswered & 16 & 1.6 & 2 & 0.2 & 67 & 7.0 & 61 & 6.4 \\
\hline
\end{tabular}

*In this table, each of the 50 images were reviewed by up to 21 participants (maximum of 1,050 images) $\mathrm{BCC}=$ basal cell carcinoma; $\mathrm{SCC}=$ squamous cell carcinoma; $\mathrm{SK}=$ seborrheic keratosis. 


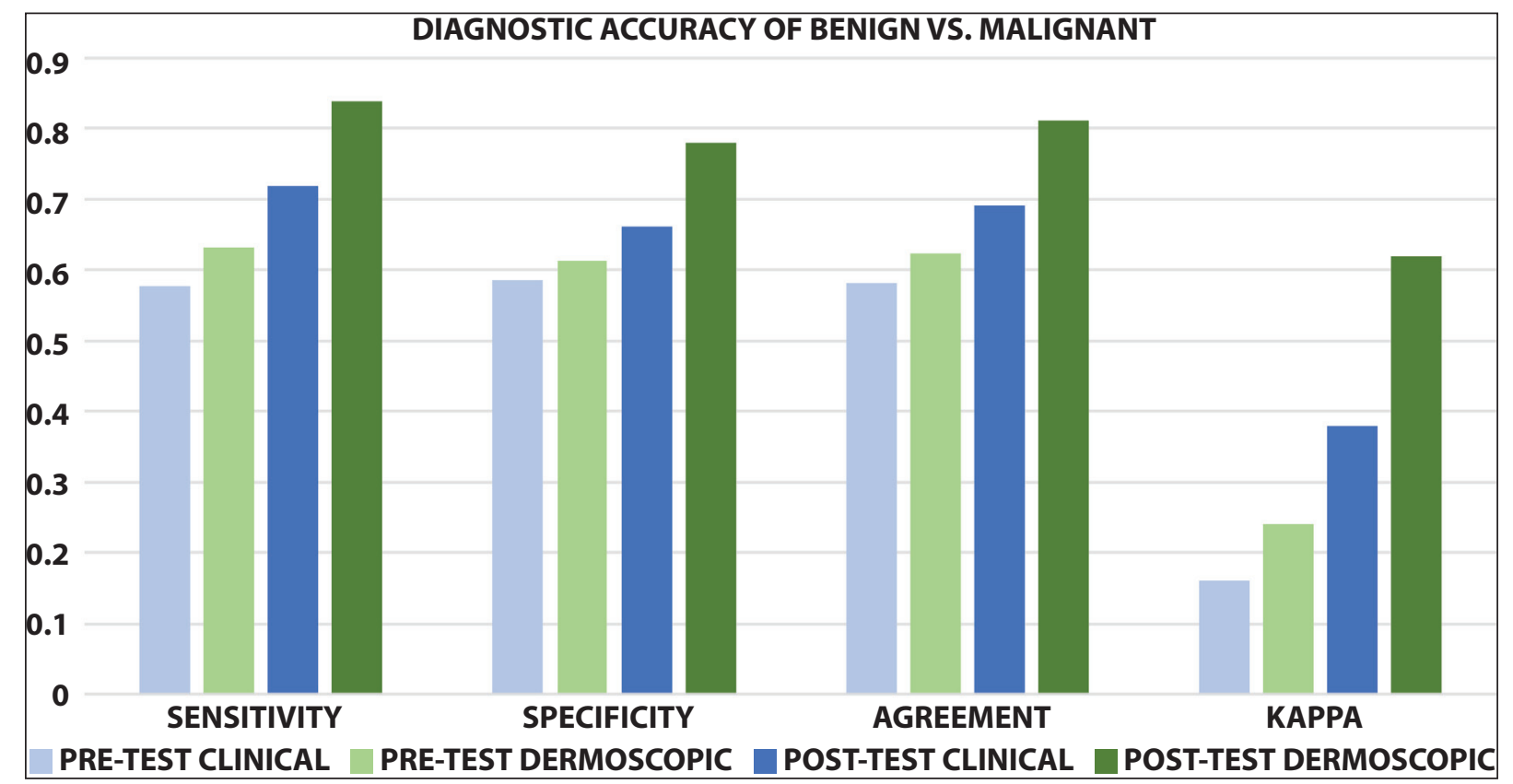

Figure 2. Diagnostic accuracy of benign vs malignant. An increase in sensitivity and specificity in differentiating skin lesions as benign vs malignant was observed after the two-day skin cancer and dermoscopy training.

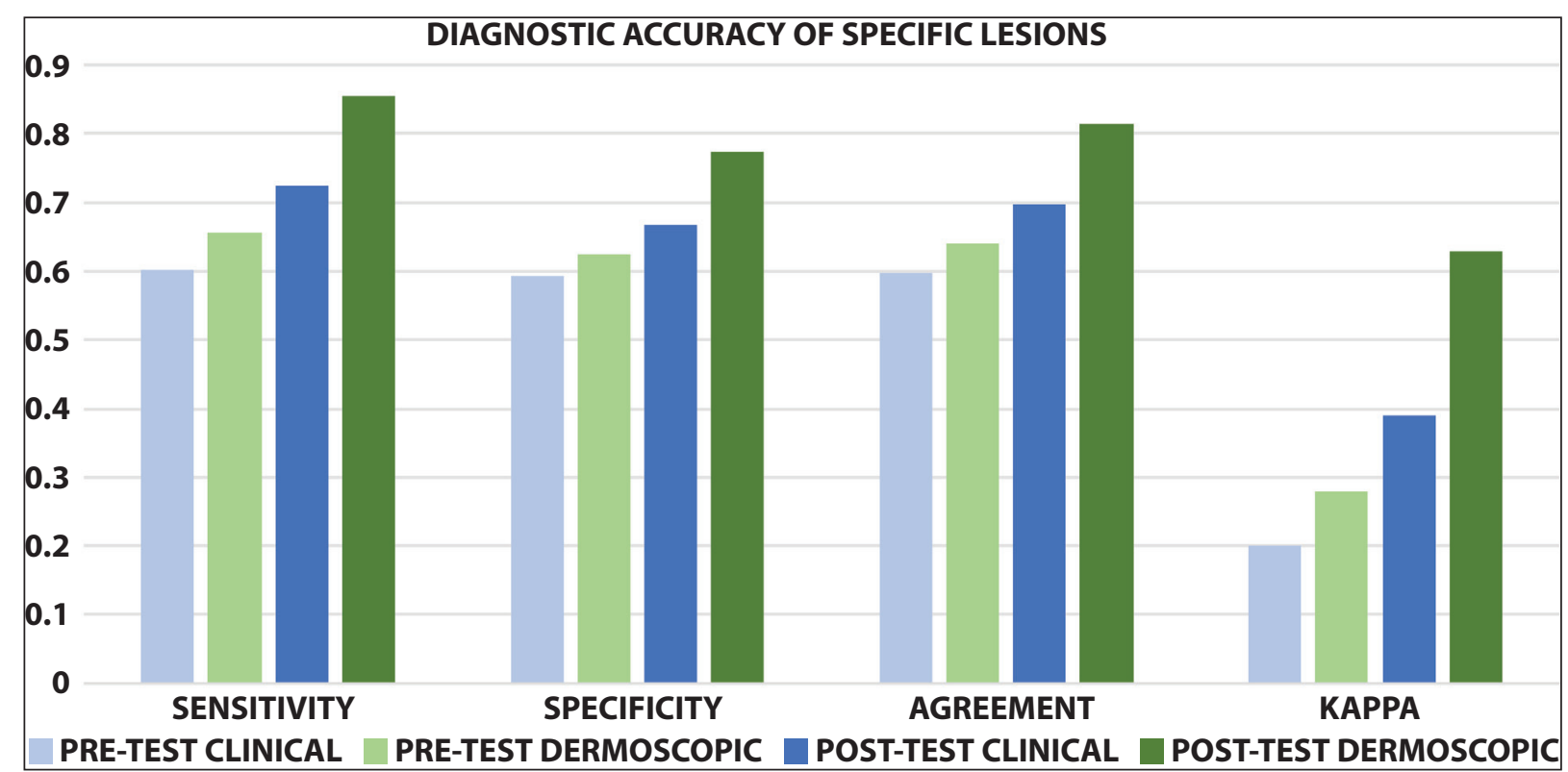

Figure 3. Diagnostic accuracy of specific lesions. An increase in sensitivity and specificity in diagnosing specific skin lesions was observed after the two-day skin cancer and dermoscopy training.

lesions as "high" or "extremely high" increased by $19 \%$ (30.9\% to $49.8 \%$; OR: 2.22 ; $95 \%$ CI: $1.84-2.67$; P < 0.0001) for clinical images, and $28 \%$ (30.9\% to 59\%; OR: $3.22 ; 95 \%$ CI: 2.67-3.86; P <.0001) for dermoscopic images (Figure 4). Furthermore, confidence was correlated with diagnostic accuracy. Considering confidence as a continuous measurement from 1 ("extremely low") to 5 ("extremely high"), the correct diagnosis rate increased by $34.4 \%$ for every 1-point increase in confidence (overall OR: 1.34; 95\% CI: 1.27-1.43).
During the skin cancer screening, the majority of participants continued to report high levels of confidence $(53.2 \%$ for clinical images, $73.7 \%$ for dermoscopic).

Three-Month Follow-up

To evaluate the effects of the intervention on the participants' clinical practices, a 3-month follow-up of the PCPs was planned to learn whether the training was serving the target population. However, most of the participating PCPs were 


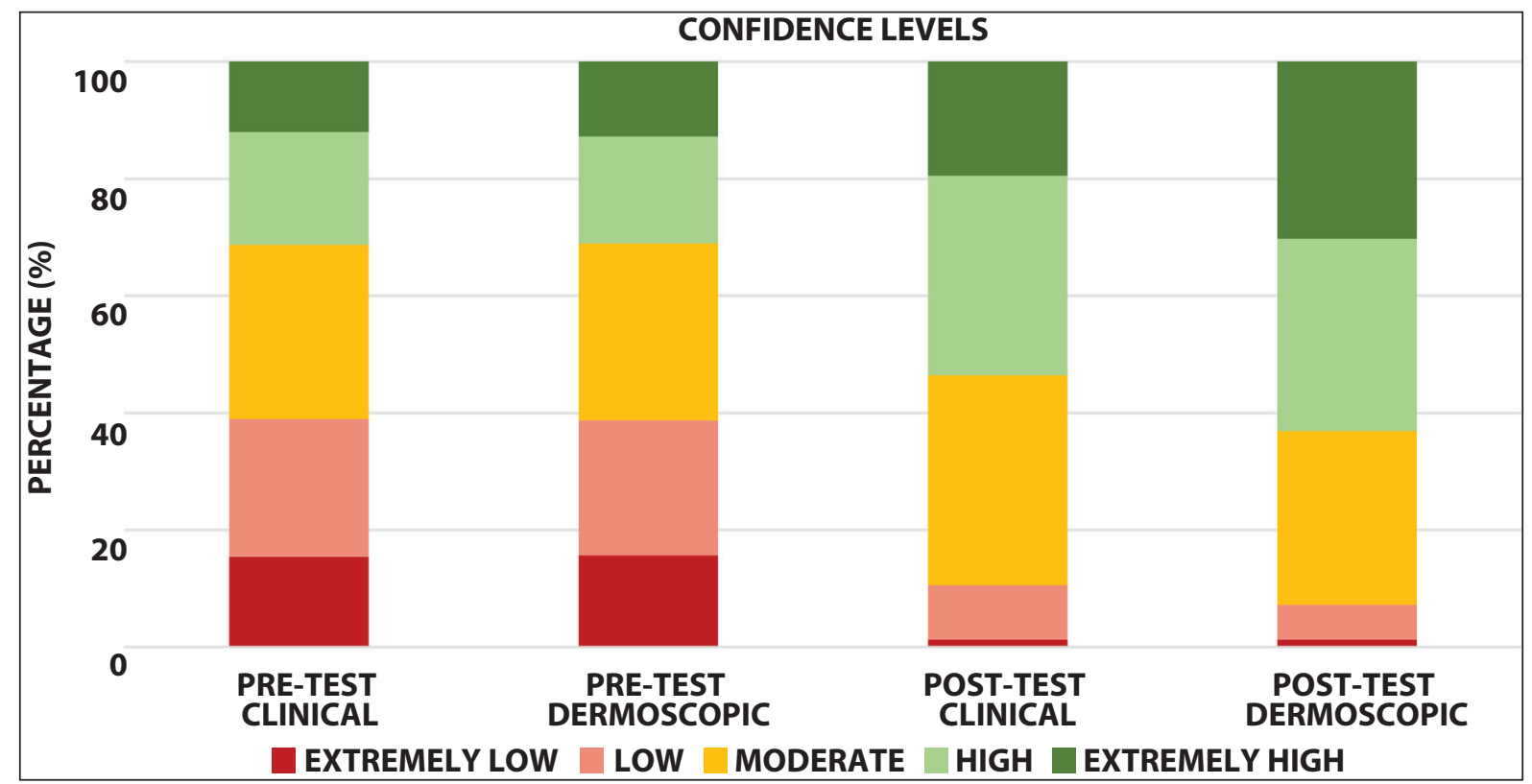

Figure 4. Confidence levels among participants. An increase in physician confidence in diagnosing skin lesions was observed after the two-day skin cancer and dermoscopy training.

lost to follow-up, and the lists with ICD-10 codes were only provided by 2 of the participating physicians.

\section{Discussion}

Timely and accurate skin cancer diagnosis continues to be a clinical challenge, especially in underserved populations, rural areas, and developing countries where resources and geographic locations limit access to specialized healthcare. The use of dermoscopy increases the diagnostic accuracy of skin cancer by revealing structures and features otherwise invisible to the naked eye [11]. In the primary care setting, dermoscopy has been shown to improve the diagnostic accuracy for skin cancer and enhance the capacity of PCPs to appropriately triage skin lesions [3,12-15]. A randomized clinical trial found that the probability of correctly diagnosing skin lesions was 1.25 times higher in PCPs using dermoscopes compared to PCPs using only naked-eye examination [16]. Training PCPs in dermoscopy not only advances physician knowledge and diagnostic skills, but can also benefit their community, where he or she may be the only healthcare provider. In our study, the 6 hospitals served about 111,175 persons, all of whom resided in municipalities where PCPs were the only healthcare providers.

Studies have revealed that mastery-learning courses in dermoscopy led by dermatologists improve diagnostic accuracy, increase physician confidence, and decrease referrals of benign lesions [17-21]. Similarly, our study demonstrated that PCPs increased their sensitivity and specificity for detecting skin cancer after participating in the 2-day course on skin cancer and dermoscopy. This highlights the already known utility of dermoscopy in the detection of skin cancer by PCPs and emphasizes the impact that an educational training program may have, even when it is as short as a few days. On the other hand, confidence, which is defined as the degree of certainty in the correctness of a diagnosis, is usually influenced by a variety of factors, including experience, level of training, and self-assurance [22]. The addition of dermoscopy to the clinical examination has been shown to reduce doubt and increase confidence, especially when evaluating skin lesions that are clinically challenging, but clearly benign or malignant under dermoscopy [22]. Our results demonstrate that confidence improved among the majority of participating PCPs after being trained in skin cancer and dermoscopy, and was correlated with increased diagnostic accuracy. This also suggests that confidence and knowledge can be further consolidated and maintained over time when additional rehearsals or trainings occur.

Conventionally, skin cancer diagnosis and dermoscopy has been taught through traditional lectures and problem-based learning using images of skin lesions. In this study we used a combined approach incorporating passive (ie, traditional lectures) and active (ie, problem-based) learning strategies, followed by experiential learning with live patient encounters (LPE) during a skin cancer screening event. Although there are several forms of active learning, we included problem-based learning and experiential learning with LPE in a one-on-one training as an approach to meet the 4 key requirements of active learning: 1) activating prior knowledge; 2 ) involving the majority of students; 3 ) promot- 
ing metacognition to increase awareness of strengths and weaknesses as learners; and 4) providing participants with feedback about their learning [23]. LPE is an active learning strategy rated by students as better than problem-based learning, which can result in increased performance and learning [24]. This one-on-one training ensured that the providers felt comfortable handling and using a dermoscope in a real clinical setting before incorporating it in their clinical practice.

Our study has several limitations. First, we acknowledge that this was a pilot study, the number of participants was small, and the sample was a non-probability-based convenience population, selected based on the geographic location of the 6 municipalities. Thus, our sample may not represent the target population. Second, the secondary objective of the study was to follow up with the PCPs after 3 months for reevaluation and to record the number of skin cancer diagnoses made since the initial training. However, this objective proved to be challenging since the majority of participants were lost to follow-up. Possible reasons for this include a lack of interest and the temporality of some of the providers, as many work for less than a year during their social service. Therefore, we suggest that educational initiatives abroad should involve local academic or governmental entities that can implement and maintain such programs in a more rigorous form. Another alternative would be to provide the educational initiative as part of the curriculum in medical schools during the last year of training (eg, internship). Furthermore, in the demographic survey related to skin cancer practices and knowledge, a large proportion of questions went unanswered by PCPs, limiting the results of this questionnaire.

\section{Conclusions}

PCPs play a key role in healthcare across the globe, especially those of developing countries and rural areas, including Latin America. We conclude that appropriate training in skin cancer diagnosis and dermoscopy with active learning strategies can increase physician knowledge and confidence. This may ultimately decrease healthcare costs by reducing the number of unnecessary referrals, while improving the early detection of skin cancer in underserved areas lacking healthcare specialists.

\section{References}

1. Goulart JM, Quigley EA, Dusza S, et al; INFORMED Group. Skin cancer education for primary care physicians: a systematic review of published evaluated interventions. J Gen Intern Med. 2011;26(9):1027-1035. DOI: 10.1007/s11606-011-1692-y. PMID: 21472502.
2. Menzies SW, Ingvar C, McCarthy WH. A sensitivity and specificity analysis of the surface microscopy features of invasive melanoma. Melanoma Res. 1996;6(1):55-62. DOI: 10.1097/00008390199602000-00008. PMID: 8640071

3. Argenziano G, Soyer HP. Dermoscopy of pigmented skin lesions--a valuable tool for early diagnosis of melanoma. Lancet Oncol. 2001;2(7):443-449. DOI: 10.1016/S1470-2045(00)00422-8.

4. Argenziano G, Puig S, Zalaudek I, et al. Dermoscopy improves accuracy of primary care physicians to triage lesions suggestive of skin cancer. J Clin Oncol. 2006;24(12):1877-1882. DOI: 10.1200/JCO.2005.05.0864. PMID: 16622262.

5. Westerhoff K, McCarthy WH, Menzies SW. Increase in the sensitivity for melanoma diagnosis by primary care physicians using skin surface microscopy. Br J Dermatol. 2000;143(5):1016-1020. DOI: 10.1046/j.1365-2133.2000.03836.x. PMID: 11069512.

6. Menzies SW, Emery J, Staples M, et al. Impact of dermoscopy and short-term sequential digital dermoscopy imaging for the management of pigmented lesions in primary care: a sequential intervention trial. Br J Dermatol. 2009;161(6):1270-1277. DOI: 10.1111/j.1365-2133.2009.09374.x. PMID: 19747359.

7. Kittler H, Pehamberger H, Wolff K, Binder M. Diagnostic accuracy of dermoscopy. Lancet Oncol. 2002;3(3):159-165. DOI: 10.1016/S1470-2045(02)00679-4. PMID: 11902502.

8. Bafounta ML, Beauchet A, Aegerter P, Saiag P. Is dermoscopy (epiluminescence microscopy) useful for the diagnosis of melanoma? Results of a meta-analysis using techniques adapted to the evaluation of diagnostic tests. Arch Dermatol. 2001;137(10):13431350. DOI: 10.1001/archderm.137.10.1343PMID: 11594860.

9. Vestergaard ME, Macaskill P, Holt PE, Menzies SW. Dermoscopy compared with naked eye examination for the diagnosis of primary melanoma: a meta-analysis of studies performed in a clinical setting. Br J Dermatol. 2008;159(3):669-676. DOI: 10.1111/j.1365-2133.2008.08713.x. PMID: 18616769.

10. Sanclemente Mesa G, Hernández Garzón GE. Altos índices de radiación ultravioleta en Medellín y en una localidad del oriente antioqueño (COLOMBIA). 2010.

11. Kittler H PH, Wolff K, Binder M. Diagnostic accuracy of dermoscopy. Lancet Oncol. 2002;3(3):159-165. DOI: 10.1016/ S1470-2045(02)00679-4.

12. Lallas A, Zalaudek I, Argenziano G,, et al. Dermoscopy in general dermatology. Dermatol Clin. 2013;31(4):679-94, x. DOI: 10.1016/j.det.2013.06.008. PMID: 24075553.

13. Argenziano G, Soyer HP, Chimenti S, Argenziano G, Ruocco V. Impact of dermoscopy on the clinical management of pigmented skin lesions. Clin Dermatol. 2002;20(3):200-202. DOI: 10.1016/ S0738-081X(02)00234-1.

14. Argenziano G. The impact of dermoscopy on the management of pigmented skin lesions: the role of follow-up. J Am Acad Dermatol. 2005;52(1):178; author reply 9-80. DOI: 10.1016/j. jaad.2004.06.032. PMID: 15627115.

15. Braun RP, Rabinovitz HS, Oliviero M, Kopf AW, Saurat JH. Dermoscopy of pigmented skin lesions. J Am Acad Dermatol. 2005;52(1):109-121. DOI: 10.1016/j.jaad.2001.11.001. PMID: 15627088

16. Koelink CJ, Vermeulen KM, Kollen BJ, et al. Diagnostic accuracy and cost-effectiveness of dermoscopy in primary care: a cluster randomized clinical trial. J Eur Acad Dermatol Venereol. 2014;28(11):1442-1449. DOI: 10.1111/jdv.12306. PMID: 25493316. 
17. Argenziano G, Puig S, Zalaudek I, et al. Dermoscopy improves accuracy of primary care physicians to triage lesions suggestive of skin cancer. J Clin Oncol. 2006;24(12):1877-1882. DOI: 10.1200/JCO.2005.05.0864. PMID: 16622262.

18. Menzies S, Emery J, Staples M, Davies S, McAvoy B, Fletcher $\mathrm{J}$, et al. Impact of dermoscopy and short-term sequential digital dermoscopy imaging for the management of pigmented lesions in primary care: a sequential intervention trial. $\mathrm{Br} \mathrm{J}$ Dermatol. 2009;161(6):1270-1277. DOI: 10.1111/j.13652133.2009.09374.x. PMID: 19747359.

19. Robinson JK, Jain N, Marghoob AA, et al. A randomized trial on the efficacy of mastery learning for primary care provider melanoma opportunistic screening skills and practice. J Gen Intern Med. 2018;33(6):855-862. DOI: 10.1007/s11606-018-4311-3. PMID: 29404948.

20. Robinson JK, MacLean M, Reavy R, Turrisi R, Mallett K, Martin GJ. Dermoscopy of concerning pigmented lesions and primary care providers' referrals at intervals after randomized trial of mastery learning. J Gen Intern Med. 2018;33(6):799-800. DOI: 10.1007/s11606-018-4419-5. PMID: 29637481.
21. Secker LJ, Buis PA, Bergman W, Kukutsch NA. Effect of a dermoscopy training course on the accuracy of primary care physicians in diagnosing pigmented lesions. Acta Derm Venereol. 2017;97(2):263-5. DOI: 10.2340/00015555-2526. PMID: 27572816.

22. Benvenuto-Andrade C, Dusza SW, Hay JL,,et al. Level of confidence in diagnosis: clinical examination versus dermoscopy examination. Dermatol Surg. 2006;32(5):738-744. DOI: 10.1097/00042728-200605000-00034. PMID: 16706773.

23. Medina MS. Making students' thinking visible during active learning. Am J Pharm Educ. 2017;81(3):41. DOI: 10.5688/ ajpe81341. PMID: 28496261.

24. Rohlfsen CJ, Sayles H, Moore GF, et al. Innovation in early medical education, no bells or whistles required. BMC Med Educ. 2020;20(1):39. DOI: 10.1186/s12909-020-1947-6. PMID: 32033553.

25. Landis JR, Koch GG. The measurement of observer agreement for categorical data. biometrics. 1977;33(1):159-74. DOI: $10.2307 / 2529310$. 